\title{
Lesson Study: A Tool for an Improved Instructional Design in Teaching Integration by Parts
}

\author{
Daisy Lyn F. Mariano ${ }^{a}$, Jayson G. Barsana ${ }^{b}$, Kristine Anne C. Dimaculangan ${ }^{c}$, Leroy A. Flores ${ }^{d *}$, Freddie \\ Parto $^{\mathrm{e}}$, Oliver G. Marianof ${ }^{\mathrm{f}}$ Levi Elipane ${ }^{\mathrm{g}}$
}

${ }^{\text {a} P a r a d a ~ N a t i o n a l ~ H i g h ~ S c h o o l, ~ V a l e n z u e l a ~ C i t y, ~ P h i l i p p i n e s ~}$

${ }^{\mathrm{b}}$ Tagbacan National High School, Catanauan, Quezon, Philippines

${ }^{c}$ De La Salle Lipa Integrated School, De La Salle Lipa, 1962 JP Laurel Highway, Lipa City, Batangas, Philippines

${ }^{\mathrm{d}}$ President Ramon Magsaysay State University, Iba, Zambales, Philippines

${ }^{\mathrm{e}}$ San Roque National High School, San Roque, Antipolo City, Philippines

${ }^{\mathrm{f}}$ Sitero Francisco Memorial National High School, Philippines

${ }^{g}$ College of Graduates Studies and Teacher Education Research, Philippine Normal University, Manila, Philippines

d*floresleroy16@gmail.com

Article History: Received: 10 November 2020; Revised 12 January 2021 Accepted: 27 January 2021; Published online: 5 April 2021

\begin{abstract}
This study aimed to develop instructional design in teaching the Integration by Parts in Calculus. By engaging in a Lesson Study, the researchers underwent careful planning of the design, executed it through a research lesson, noted key observations during the delivery of the lesson, and conducted a post-lesson conference. From the observations and insights during the post-conference, two themes emerged from where recommendations were drawn. The first theme pivoted on the propensity of teaching Integration by Parts as highly procedural and mechanical despite attempts at activating students' higherorder thinking. However, the extent to which the tabular method could be advantageous should be explained to the students to clarify misconceptions about using it as a shortcut in performing Integration by Parts. The second theme revolved around how supportive classroom environment and the use of Tabular Method made the students more engaged. Nevertheless, providing learning experiences where students can be work on higher-order thinking and where they can process results of their collaboration was recommended to be incorporated in the instructional design. Generally, both Tabular and Conventional Methods play a crucial role in developing students' mastery of this integration technique and may eventually allow them to make connections to the real world
\end{abstract}

Keywords: Lesson Study; Teaching of Integration by Parts; Tabular Method; Instructional Design

\section{Introduction}

Over the past years, Calculus has played a significant role in the continuing advancement of human knowledge in the field of Mathematics and other related disciplines. This undeniable fact makes itself deserving of the priority spots in higher education programs focusing on STEM (Science, Technology, Engineering, Mathematics) Education. However, university undergraduate students still do not perceive its obvious importance; and instead, consider it as an abstract and difficult subject. Ferrer [1] noted that students have their struggles and difficulties when it comes to learning Calculus. One of the topics in Integral Calculus where persisting difficulty among students is observable is the various techniques of integration. In particular, integration by parts, as a fundamental integration technique is where students' struggle starts to emerge. The technicality of the topic and its connection to previously learned integration rules make it difficult for them to absorb. However, a promising alternative in the teaching of integration by parts, called Tabular Integration, may be introduced to students in anticipation of a more solid understanding of the lesson. Maneuvering teaching practices for this lesson into something that could give better student outcomes may be included as part of reconstructing instructional design.

Nevertheless, at the tertiary level, enhancement of teaching practice towards achieving common goals is often set aside since most university instructors/lecturers plan their classroom activities in isolation. This limits the opportunities that Lesson Study (LS) can offer especially to professors handling higher tertiary courses like Calculus. This situation motivated the researchers to engage in Lesson Study in exploring how the teaching of Integration by Parts, in the course Integral Calculus was taken by the third year Mathematics Education students, can be further improved.

This study aimed to describe how the teaching of integration by parts may be improved by introducing Tabular Integration as an alternative method through LS. 


\section{Literature Review}

\section{Tabular Method in Integration by Parts}

Some studies have shown that students had difficulties in understanding Calculus [2,3], which includes Integration by Parts [4]. As such, studies concerning the enhancement of teaching and learning Calculus among university students were found available in the stacks of literature. One of them is done by Palomares [5], who found out that Cooperative Learning helps improve the teaching of Integral Calculus. Not only that, his study also revealed that students have increased performance upon their exposure to a cooperative classroom environment.

In the same manner, when Yuliana et.al [6] tried Guided Discovery Learning in teaching Integral Calculus, it showed marked improvement in students' achievement when it comes to selected topics in integration including Integration by Parts.

Also, Borji, Radmehr, and Font [7] found that conceptual teaching leads to more sustainability in understanding Calculus, as compared with procedural teaching.

In her study, Mrayyan [8] considered the use of Tabular Integration by Parts as a good shortcut technique in integration. With this, she recommended for it be taught in classrooms and be discussed in more textbooks and resources in Integral Calculus.

Likewise, Tisdell [9] put forward the use of tabular integration as an alternative tool towards performing integration by parts. He managed to present how the said technique may be applied in solving particular problems that involve repeated integration.

Related to this is the work of Noh et.al. [10] which focused on the implementation of Tabular Integration by Parts on the teaching and learning process for selected engineering students. Their experimental study revealed promising results in favor of Tabular Integration by Parts. Students who were exposed to Tabular Integration by Parts had improved mastery and increased confidence in doing integration.

The cited studies indicate that optimum performance in Calculus can be achieved by the students when they are taught using appropriate methods or when they are exposed to well-planned and structured instruction.

\section{Productive Pedagogies}

Part of developing a well-planned and structured instruction is to consider elements of the Productive Pedagogies (PP) Framework. PP are classroom strategies that teachers can use to focus instruction and improve student outcomes [11]. Developers of the PP framework have postulated four dimensions that characterized effective teaching, namely: Intellectual Quality, Connectedness, Supportive Classroom Environment, and the Recognition of Difference. Of particular interest in this study are the dimensions of Connectedness and Supportive Classroom Environment.

Connectedness is the dimension of the PP framework that deals with how to make school studies more relevant in addressing issues outside of school. Elements of this dimension are knowledge integration, background knowledge, connectedness to the world, and a problem-based curriculum. Integrated school knowledge is identifiable when lessons integrate a range of subject areas, while an explicit linking of background knowledge with new knowledge characterizes high-connection lessons. Connectedness describes the extent to which the lesson has value and meaning beyond the instructional context, making a connection to the wider social context within which students live, while a problem-based curriculum is one in which students are presented with specific practical, real, or hypothetical problems to solve [11].

A supportive classroom environment is characterized by student direction, social support, academic engagement, self-regulation, and explicit quality performance criteria. Student direction means that students determine specific activities or outcomes of the lesson, while academic engagement is demonstrated by students when they are attentive and show enthusiasm in doing assigned work. Also, there is social support when the classroom has an atmosphere of mutual respect and support between teacher and student, and among students. Self-regulation is present when the direction of student behavior is implicit and self-regulatory. Lastly, explicit quality performance criteria are frequent, detailed, and specific statements about what the students are to do and to achieve [11].

Several studies have revealed the effectiveness of the PP framework in achieving quality classroom instruction [12] and in improving teacher education $[13,14,15]$. 


\section{Methodology}

A well-known practice that is proven to help teachers improve their teaching practices is Lesson Study (LS). As explained by Hiebert et. al. [16], LS is a teaching improvement and knowledge-building process that has origins in Japanese elementary education. Also, Lewis [17] suggests that LS creates multiple pathways for learning that lead to instructional improvement.

LS provides avenues for increased knowledge on subject matter and instruction, improved ability to observe students, as well as a stronger connection of daily practice to long-term goals. Recognizing this fact, the popularity of conducting LS among elementary and secondary schools has been continuously spreading around the globe [17].

LS, as described by Burghes and Robinson [18], is a professional whose aim is to improve the quality of teaching and learning among classrooms. It involves teachers who collaboratively work on the plan, observe, analyze, and reflect on real classroom practices towards their improvement.

Also, Verhoef and Goei [19] concluded that LS does not only promote a focus on student thinking and learning but also on best learning materials and teaching methods teachers may use in their classrooms.

Moreover, Cerbin and Kopp [20] created a model of LS that is specifically designed for a college classroom. In their model, they clearly emphasized the idea that LS can be used in tertiary levels as a teaching improvement process since it allows scaffolding of reflective practice where instructors can analyze learning goals, design learning experiences, and revise the lesson design to improve learning.

These vividly reflect the notion that LS may be considered as a tool that is flexible enough to address the need to improve instruction and eventually the quality of learning across various disciplines at any level of the educational system. Several LS research that incorporate the PP Framework have also been undertataken; see [21, 22].

\section{Participants and Locale of the Study}

The group involved in conducting this LS is composed of six members with one of them as the demonstration teacher. This LS was a partial fulfillment of the requirements in a Ph.D. course. The LS was conducted among 15 third year college students of BSE-Mathematics of Global Reciprocal Colleges whose age ranges from 19 to 22 years old. The school os located at Caloocan City, Metro Manila. In the critiquing of the conduct of the research lesson, eight Ph.D. in Mathematics Education students who were in the same course (but were not the researchers for this paper) and their professor in the course Math Ed 803 took part in observations, and sharing insights and suggestions on the research lesson - these participants are the LS team.

\section{The Lesson Study Cycle}

In conducting the LS, the proponents were guided by the model suggested by Elipane [23], which includes steps such as 1) Goal-setting, 2) Writing the Lesson Plan, 3) Research Lesson, and 4) Lesson Debriefing. In his model of LS, a revision of the lesson may be done, but not necessary.

\section{Goal-setting}

The proponents chose "Integration by Parts" as the LS topic since it is a very timely lesson for the students. The development of the lesson was considered by the researchers in teaching integrals using the two methods traditional and tabular method. The following were the objectives of the lesson: (1) find integral using integration by parts; (2) apply column integration and tabular integration as an alternative technique to calculate integrals; and (3) show cooperation in all activities.

\section{Writing the Lesson Plan}

The researchers collaborated in writing the lesson plan from the motivation, review, and practicing skills parts down to the lesson proper. The lesson plan included a question that intends for the students to realize that the given problem cannot be solved using their previous knowledge in calculating integrals.

A discussion of the lesson was planned systematically through brainstorming. Each of the researchers contributed problem-solving items in calculating integrals. The traditional and tabular methods have been finalized as the two methods the students must use in calculating integrals.

The concepts of the two methods in teaching integration by parts as the techniques in calculating integrals were established for the benefit of the students. These methods helped the researchers to find which of the two will make a difference in learning integration by parts. 


\section{Research Lesson}

For the research lesson, one of the authors served as the demonstration teacher. Other proponents, together with their professor, observed, noted, and provided comments on the teaching process and flow of the demonstrations including observations on the demo-teacher, student participants, the chosen lesson, and other significant and remarkable observations.

\section{Lesson debriefing or post-lesson discussion}

After the research lesson, a post-lesson debriefing or discussion led by the professor, who acted as moderator, was conducted. The moderator asked first the demonstration teacher about the experience and impression regarding the whole LS cycle and the research lesson. This was followed by the reflections of the other members of the group about the preparation, the group's collaboration, and the demonstration proper. Lastly, the other observers gave comments to the demonstration teacher, students' participation, and suggested how to improve the lesson

\section{Results and Discussions}

This study aimed at using lesson study as a tool in developing an improved instructional design in teaching Integration by Parts, anchored on some elements of the PP Framework. While some members of the LS team have questioned the appropriateness of LS at the College level, results of the post-discussion revealed that it is a highly potent tool in developing an effective instructional design even in lessons that are very technical like Integration by Parts.

Through the LS, the researchers came across the following themes: (1) The teaching of Integration by Parts remained to be superficial and mechanical despite attempts of activating students' prior knowledge; and (2) The importance of a supportive classroom environment and the use of Tabular Integration by Parts made the students more academically engaged.

\section{The teaching of Integration by Parts remained to be procedural despite attempts of activating students' higher-order thinking}

In the discussion of Integration by Parts, the teacher presented two methods of solving; the standard method and the tabular method. The tabular method was deemed an easier way of integrating the given functions, as its procedure is relatively easier to follow than that of the standard method; hence, it can be considered a short-cut technique in solving by Integration by Parts. However, observations of the LS team revealed that introducing the tabular method very early in the discussion may hinder the development of a deep understanding of what Integration by Parts (IbP) is all about. It was thought of to have such an effect as the students tend to simply follow procedures without really understanding what IbP is and why such a tabular method works. As commented by some of the teacher observers and post-discussion facilitator:

Teacher-observer 1: I was amazed at how the students easily believed any technique shown to them. When the tabular method was shown to them, they were so happy and amazed, but no one asked why it works. Not even one student asked, "why is it like that? Why is it possible?" No one asked. They were all just happy that there is a shorter method. I guess our students grow up to be like that; they become very dependent on procedural fluency, but the conceptual understanding is missing.

Teacher-observer 2: When you (referring to the teacher-demonstrator) introduced the shortcut method (tabular method) immediately after giving one example using the standard method, the focus was shifted at once to the shortcut. I think when we teach we should ensure that the standard method is mastered (by the students) first before teaching the short-cut method. Because when you give the short-cut right away, there will be no more focus on the standard method.

Post-discussion Facilitator: The use of the tabular method shows a lever potential, which means it can make the work easier, but we have to be very careful. We can make the work easy but then again the student should not forget the concept. Again it's very technical, it can be some sort of a short cut but if the student focuses on that then we're not helping them. The lever potential is that it can leverage the work more to make it easier... So we see here that the level potential means that some things that are technical or mechanical, it's like something that the computer can do, can be done using a shortcut. But then again the higher-order thinking should also be done by the students. It cannot be missing.

Based on the comments, it can be inferred that while the use of shortcut techniques provides a lever potential or the ability to make solving easy, such techniques should be used with caution so as not to hinder the development of a deep understanding of the subject matter. 
The aforementioned comments during the post-discussion also run in consonance with how the students utilized the two methods of Integration by Parts. In the group activity where students, in groups of four, were given some functions to solve using IbP, the teacher instructed that they should use both methods. It was noticeable that most of the groups started with the tabular method, then used the standard method to merely check if the answer they obtained using the tabular method is correct. Furthermore, when the students discussed their solutions, the explanations did not reflect a clear understanding of what IbP is all about. The explanation focused more on the mechanical steps in solving using the tabular method, which is a manifestation of a shallow understanding of IbP.

Such a shallow understanding of IbP may also be associated with the inability to establish a clear link between the students' prior knowledge about integration and the use of IbP. Before the main topic Integration by Parts was introduced to students, the teacher provided a formative assessment wherein students were given a problem set about integration. There were three items given; two of which can be solved using Integration by Substitution while the third one can be done thru Integration by Parts. The plan was to make the students realize that some functions cannot be integrated using Substitution; hence, there is a need for another method of integration.

The teacher was successful in making the students recall the process of Integration by Substitution and in realizing that the third function cannot be integrated using the same method, but the transition from the use of Integration by Substitution to the use of Integration by Parts was not highly evident in the flow of discussion. Such a point was raised by some members of the Lesson Study team.

Group member 1: When we were in the planning stage, we decided that the last example should be the transition to the Integration by Parts...that was the plan. So the student is going to try, but even though they try their best, all of their knowledge about integration should lead to not being able to solve. So that's why there will be another method. The question they should have raised, "Sir we cannot get the answer ... sir there might be another method" ... and that would be the introduction of the lesson... that's the plan.

Teacher-observer 3: Just like what was shared by the group member, the transition. I was waiting for that from the outputs of the groups that's where the other method will come out. That's where the lesson will be introduced.

Post-discussion Facilitator: My comment on the review, is that you can do that in many different ways. It can also be thru formative (assessment), but I have to agree with others that you should have given more time for students to delve into the second one leading to integration by parts because that is really the springboard.

Teacher-observer 5: First of all, on the review part, the students should have been led for them to review the concept. Do not give it right away. Because the review part is actually the unlocking of difficulties, it is actually your transition from one part of the lesson to the other. Because if that transition is not smooth there may be problems along the way.

The comments presented pointed out the importance of effective use of background knowledge to support connectedness between the previous lesson and the new topic. While the review process was somehow successful in making students remember the previous method of integration which is by substitution, its connection to the new method which is Integration by Parts was not established.

Another point raised by the observers was the importance of knowledge integration to support connectedness between the two methods of integrating by parts, and even with making meaning of the context of integration by parts. As one observer has pointed out:

Teacher-observer 6: I was intrigued by the tabular method so I looked it up to check on its restrictions. If I were to teach this lesson, maybe I would have started with tabular then I will link it to the formula that was given because there is a link... why it is $u v$ [product of two functions denoted by $u$ and $v$ ], why it is solved downwards, it has a link with $u v$ and $u d v$ [function $u$ multiplied by the derivative of function $v$ ]. Even the use of plus and minus has a relationship. So, that's it; we should not be simply giving shortcuts, but we should establish the link. Like the derivation that you presented, the link is also there. It also has a link with tabular. So it's like, if I were the teacher since the students have seen the formula, they would be passive already. They would just want to be answered. But if I could start it with tabular, then, from tabular to standard, then they will discover how..why does tabular work like that...

Post-discussion Facilitator: But the tabular is like a shortcut, so I think it's better to start with the standard method.

Teacher-observer 6: It can also be that way, as long as the students will be able to link tabular with the standard so that it is not merely taught. Then maybe their task by the group is to find out the restrictions in using 
the tabular method. And then they will be able to see that the formula is not just a formula, but it will make sense to them.

The knowledge integration should be very evident to establish the connection between the two methods, allowing the students to make meaning of their learning. In addition, knowledge integration is also important to show the connectedness of integration by substitution and integration by parts, and of having a deeper understanding of what integration by parts is all about.

\section{The provision for a supportive classroom environment and the use of Tabular Integration by Parts made the students more academically engaged.}

One evidence of learning is an active academic engagement of students which can be achieved thru a supportive classroom environment. In the conduct of the study, it was very observable that the teacher provided a supportive classroom environment through his personality, and also through some teaching strategies he employed.

Even though it was the first time for the teacher and the students to meet, the former was able to establish rapport with the latter and such a positive connection encouraged a high level of engagement among the learners. As cited by some observers:

Group member 2: Now in terms of the response of the students it was nice because even though you've met only now you were able to get their full attention, and they were able to follow the instructions. They were listening and during the group activity all of them were doing the task, no one was inattentive.

Teacher-observer 7: Your facial expression, you were able to use it. You have a happy disposition so the students were also happy. They show a willingness to learn.

Since the teacher was able to establish a non-threatening classroom environment, the students had no hesitations in participating in the discussions and the group activities, even in the presence of a group of observers.

Another evidence of a supportive classroom environment was the teacher's use of cooperative learning and the vertical way of thinking strategies. The teacher asked the students to work in groups both for the preparatory activity and for the exercises on the use of integration by parts. He also utilized the classroom thinking strategy by working vertically - which posits that there is a difference when students are sitting down working on a task or when they are standing up [24]. Sheets of manila paper were posted on the wall where the students would write their solutions; hence, the students had to remain standing to be able to write the solutions. Such a strategy promoted maximum participation among the members of the group.

Comments of the LS team affirmed the importance of cooperative learning and the strategy of working vertically as part of a supportive classroom environment to encourage academic engagement.

Teacher-observer 4: You were able to apply a working vertical, which turned out to be really good to use as a strategy since it promoted accessibility. The group members were able to access the material, unlike when students are seated, only the ones who hold the pen or manila paper are able to write.

Post-discussion facilitator: Like we talked about the strategy of working vertically where everyone can share something, and you were able to find out that it actually helped... So ah you must be able to have more rules, are they allowed to...because some people were still writing on their desks, but then again looking at it I think it was very beneficial for the students. And also it allowed more students to be participative, cooperative.

Indeed, ensuring a supportive classroom environment is an effective means of increasing academic engagement. It would have been more concretized if the students themselves were asked how such strategies as cooperative learning and strategy of working vertically have enabled them to be more engaged in the discussion; but even in the absence of such data from the students, the observations themselves revealed the active participation of the students.

Another noticeable factor that elicited greater academic engagement among students is the use of the Tabular method of IbP. Students showed great appreciation of the said method when it was presented by the teacher. As one of the students exclaimed, "Oh, there is a shortcut!". During the group activity after the discussion of IbP, most groups used the Tabular method first. Clearly, their knowledge of the said method has enabled them to be engaged in the activity. 


\section{Conclusion}

Given the results presented in this study, it can be concluded that the use of LS is indeed a powerful tool for an effective instructional design even in lessons as technical as IbP. Through the LS, two themes anchored on the PP Framework emerged. The teaching of IbP remained to be superficial and mechanical despite attempts of activating students' prior knowledge. With this, improvements in areas of instruction where they can be engaged in higher-order thinking and where they can process results of their collaboration could be incorporated in the improved instructional design. Connection between prior and target knowledge, as well as connection between and among strategies and concepts, are integral for students to be able to gain deep understanding and higherorder thinking skills. Also, having a supportive classroom environment encourages academic engagement, as evidenced by the active participation of the students resulting from the positive disposition of the teacher and the use of cooperative learning and vertical way of thinking strategies.

Hence, the researchers recommend the use of LS even in the higher levels to enable the teachers to develop a well-planned and effective instructional design. Even in the higher levels where mathematics lessons become too technical, it is important to ensure that students develop higher-order thinking, deep knowledge, and understanding, and the ability to make meaningful connections in their learning.

\section{Acknowledgement}

The researchers would like to express their warmest gratitude and sincerest appreciation to the BSEd 3 Mathematics students of Global Reciprocal Colleges who served as the participants of the study

\section{References}

Ferrer, F.P. (2016). Investigating Students' Learning Difficulties in Integral Calculus, People: International Journal of Social Sciences, Vol. 2, No. 1.

Ruslimin, A., Masriyah, M., \& Manuharawati, M. (2019). Difficulties of Undergraduate Students to Understand of 2nd Calculus, International Journal of Trends in Mathematics Education Research, 2(1):26-30.

Tarmizi, R. A. (2010). Visualizing Student's Difficulties in Learning Calculus, Procedia - Social and Behavioral Sciences, Vol. 8, 377-383.

Borji, V. \& Font, V.(2019). Exploring Students' Understanding of Integration by Parts: A Combined Use of APOS and OSA, EURASIA J Math Sci Tech Ed., Vol. 15, No. 7.

Palomares, G. L.(2007). The Effectiveness of Cooperative Learning Method in Teaching Integral Calculus.

Yuliana, et. al. (2017). The Effectiveness of Guided Discovery Learning to Teach Integral Calculus for the Mathematics Students of Mathematics Education Widya Dharma University. Infinity Journal of Mathematics Education, Volume 6, No. 1.

Borji, V., Radmehr, F., \& Font, V.(2019). The impact of procedural and conceptual teaching on students' mathematical performance over time, International Journal of Mathematical Education in Science and Technology.

S. Mryyan. Tabular Integration by Parts: The Best Shortcut to Perform Integration. Physical Sciences and Engineering. International Journal of Current Research, 2014.

Tisdell, C. (2020). Tic-Tac-Toe and Repeated Integration By Parts: Alternative Pedagogical Perspectives to Lima's Integral Challenge. International Journal of Mathematical Education. 51. 424-430. 10.1080/0020739X.2019.1620969.

Noh, S., Nor, N., \& Ariff, M. (2019). Implementation of Tabular Integration by Parts in DBM2013 Teaching and Learning Process for Civil, Electrical, and Marine Engineering Department in Politeknik Ungku Omar. Journal Kejuruteraan, Teknologi dan Sains Sosial, Vol 1 Issue .

Education Queensland (2002). A Guide to Productive Pedagogies Classroom Reflection Manual. Brisbane: Department of Education.

Bature, I. J. \& Atweh, B. (216). Achieving Quality Mathematucs Classroom Instruction through Productive Pedagogies. International Journal of Educational Methodology, 2(1), 1-18.

Alsharif, K. M. (2011). Towards quality teacher education: Productive pedagogies as a framework for Saudi preservice teachers' training in mathematics education (Doctoral dissertation, Curtin University).

Alsharif, K. \& Atweh, B. (2012). Productive Pedagogies as Framework to Improve Preservice Teachers' Practices. The International Journal of Learning: Annual Review. 18. 223-236.

Gore, J., Griffiths, T., \& Ladwig, J. (2001). Productive Pedagogy as a Framework for Teacher Education: Towards Better Teaching.

Hiebert, J., Gallimore, R., \& Stigler, J. (2002). A knowledge base for the teaching profession: What would it look like and how can we get one? Educational Researcher, 31, 5, 3-15.

Lewis, C. (2005). How do teachers learn during lesson study? In P. Wang-Iverson \& M. Yoshida (Eds.). Building our understanding of lesson study. Philadelphia: Research for Better Schools, Inc. 
Burghes, D. \& Robinson, D. (2010). Lesson Study: Enhancing Mathematics Teaching and Learning. CfBT Education Test.

Verhoef, N. \& Goei, S. L. (2015). Lesson Study as a Tool for Teacher Learning: The Context of Combinatorial Reasoning Problems.

Cerbin, W. \& Kopp, B. (2006). Lesson Study as a Model for Building Pedagogical Knowledge and Improving Teaching. International Journal of Teaching and Learning in Higher Education, Vol. 18, No. 3, 250-257.

Lipat, J., Maog, J., Ramirez, M.A., \& Elipane, L. (2018). Teaching the Difference between Constant and Variable via Productive Pedagogies, Journal of Computer Science \& Computational Mathematics, Vol. 8, No. 4.

Artista, J., Casanova, J., de Jesus, A., Jose, K., Montero III, N., Santos, P., Dy, A., Manzano, M., Quinto, M., \& Elipane, L. (2014). Evaluating Teaching Practices Using Lesson Study with the Integration of Productive Pedagogies, Proceedings of the Korean Society of Mathematical Education 2014 International Conference on Mathematics Education, 37-49.

Elipane, L. (2012). Integrating the essential elements of lesson study in pre-service mathematics teacher education. Department of Science Education University of Copenhagen.

Liljedahl, P. (2016). Building Thinking Classrooms: Conditions for Problem-Solving. Springer International Publishing Switzerland. P. Felmer et al. (eds.), Posing and Solving Mathematical Problems, Research in Mathematics Education. 